\title{
Letter to the editor: Questioning the evidence behind the Saturation Model for testosterone replacement therapy in prostate cancer
}

\author{
Abraham Morgentaler ${ }^{1}$ (i), Abdulmaged M. Traish $^{2,3}$ (i) \\ 'Men's Health Boston, Beth Israel Deaconess Medical School, Harvard Medical School, Chestnut Hill, MA, Departments of ${ }^{2}$ Biochemistry and ${ }^{3}$ Urology, Boston University \\ School of Medicine, Boston, MA, USA
}

This is an Open Access article distributed under the terms of the Creative Commons Attribution Non-Commercial License (http://creativecommons.org/licenses/by-nc/4.0) which permits unrestricted non-commercial use, distribution, and reproduction in any medium, provided the original work is properly cited.

\section{To the editor:}

We are honored by Dr. Kim's detailed review [1] of our paper, titled, "Shifting the paradigm of testosterone and prostate cancer: The Saturation Model and the limits of androgen-dependent growth," [2] and grateful for his generous comments. However, we feel obligated to address several inaccurate comments by Dr. Kim.

It has now been 11 years since publication of this article, and over that time we have been gratified by the wealth of published research confirming all key elements of the Saturation Model. The introduction of the Saturation Model revolutionized concepts regarding the relationship of androgens and prostate growth, benign and malignant, and has served as the theoretical framework for major changes in clinical practice, including the use of testosterone (T) therapy in men with prostate cancer $(\mathrm{PCa})$. It is important for younger readers to understand that, prior to introduction of the Saturation Model, the universally held belief was the "Androgen Hypothesis", which held that higher androgen concentrations caused proportionally greater growth of prostate tissue, and that higher serum $\mathrm{T}$ meant greater PCa risk and aggressiveness.

The saturation model provided a radically different view, one that resolved an awkward paradox in which androgen deprivation clearly lowered prostate-specific antigen (PSA), yet raising $\mathrm{T}$ in hormonally intact men had little effect on PSA or prostate size. In one swoop, the Saturation Model assembled a messy assortment of clinical observations and experimental results into a coherent picture. Simply, the Saturation Model holds that prostate tissue is exquisitely sensitive to changes in serum androgens at low concentrations, and little to no sensitivity once a saturation point is reached. Clinical data indicate the saturation point for serum $\mathrm{T}$ is approximately $250 \mathrm{ng} / \mathrm{dL}$ [3-5].

The mechanisms underlying the Saturation Model include the following observations: a) $\mathrm{T}$ or its derivative, $5 \alpha$-dihydrotestosterone ( $5 \alpha-\mathrm{DHT})$, mediate prostatic cellular function by binding to the androgen receptors (AR). b) There is a finite number of $\mathrm{AR}$ binding sites per cell, and c) once $\mathrm{AR}$ sites are fully occupied with T or $5 \alpha$-DHT, a saturation state is achieved, beyond which increasing circulating $\mathrm{T}$ or $5 \alpha-\mathrm{DHT}$ cannot elicit additional biological activity via this mechanism [2]. Other mechanisms are possible [6], yet this relationship of androgens with $\mathrm{AR}$ is adequate to explain observed phenomena over a wide range of experimental data.

Several key studies subsequent to our 2009 publication include a placebo-controlled trial and registry data showing that men who received $\mathrm{T}$ therapy demonstrated an increase in PSA if baseline $\mathrm{T}$ was $<250 \mathrm{ng} / \mathrm{dL}$, but not if baseline $\mathrm{T}$ was $>250 \mathrm{ng} / \mathrm{dL}$ [3,4]; a saturation curve for serum PSA and T among 2,967 men seen in clinic, with a saturation point of approximately $250 \mathrm{ng} / \mathrm{dL}$ [5]; and unchanged PSA levels in 28 men on active surveillance for PCa who received $\mathrm{T}$ therapy for a mean duration of approximately 3 years [7]. At no point have we claimed the Saturation Model means T therapy is safe for all men with $\mathrm{PCa}$, since any number of additional 
factors may come into play in the complex biology of cancer, and large, controlled trials are required to demonstrate safety. However, we note now, as we did in 2009, that published experiences with $\mathrm{T}$ administration in men with $\mathrm{PCa}$, even in men with metastatic disease, appear consistent with the Saturation Model.

Dr. Kim made several criticisms regarding our 2009 paper. In every instance, we stand by our original comments, and unfortunately conclude that Dr. Kim has either failed to understand our own work, or failed to understand the underlying science of the research we cited.

1. Dr. Kim asserts in several instances that data we presented from experiments or clinical trials by others had not been intended to investigate saturation, and therefore these were taken "out of context." Of course, none of these studies investigated saturation because the saturation model did not yet exist! One of the strengths of our paper was finding data that already existed in various systems supporting saturation, but was not recognized as such.

2. Dr. Kim criticized the methodology of Ho et al. [8] in his study quantitating AR, in part because of the use of ice-cold buffer, and describing the technique as involving a radioimmunoassay (RIA). Dr. Kim appears to be unfamiliar with this methodology, which has been the gold standard for AR detection and quantitation since the 1970s. A direct radioligand binding assay is used with a synthetic ligand that does not bind to plasma proteins. No RIA is involved, and the use of ice-cold buffer is a standard biochemical method to preserve receptor binding activity, in vitro.

3. Dr. Kim suggests we selectively included supportive data from animal prostate experiments by Wright et al. [9], (shown in Dr. Kim's Fig. 2A), while neglecting to include contradictory data (shown in Dr. Kim's Fig. 2B). This is misleading, since Kim's panels A and B are from two very different experiments with different aims. We included the figure in Fig. 2A because it was most relevant to the Saturation Model, showing prostate parameters (e.g, weight) as a function of serum $\mathrm{T}$ concentrations. The data show a saturation curve as serum T increases. The experiments in Dr. Kim's panel B show the same prostate measures, but as a function of intraprostatic androgen concentrations. A saturation curve is less obvious here. However, intraprostatic androgen concentrations include non-specific protein-bound T, which may be increased in an experimental system without necessarily reflecting biological activity.

4. Dr. Kim also alleges we left out contradictory data in our description of results from Bhasin et al. [10], in which groups of men received widely varying doses of $\mathrm{T}$ injections after suppression of endogenous $\mathrm{T}$ via luteinizing hormone- releasing hormone agonist, resulting in serum $\mathrm{T}$ concentrations ranging from low to more than twice the upper limit of normal. What we showed was a graphic representation of data showing that PSA values were similar for all groups at 20 weeks of treatment despite enormous differences in serum T, arguing strongly for saturation. Dr. Kim presents an additional figure in which men treated with the lowest dose of $\mathrm{T}$ appear to demonstrate a decline in PSA compared with baseline, whereas PSA was increased in men that received higher $\mathrm{T}$ doses. Dr. Kim fails to recognize that these data are also confirmatory of the Saturation Model- PSA declines when T is reduced at concentrations below the saturation point and rises with increased $\mathrm{T}$ if baseline levels were not all above the saturation point. This is why many men in clinical practice will demonstrate an initial rise in PSA upon beginning $\mathrm{T}$ therapy.

More than a decade since its publication, the Saturation Model has turned out to be a robust description of the relationship between androgens and the prostate, and we are unaware of any compelling evidence to the contrary. At this point we conclude that the Saturation Model should no longer be considered a hypothesis, but rather an accurate framework describing the relationship of androgens and the prostate.

\section{CONFLICTS OF INTEREST}

The authors have nothing to disclose.

\section{AUTHORS' CONTRIBUTIONS}

Abraham Morgentaler and Abdulmaged M. Traish have contributed to research conception and design as well as data acquisition. They contributed equally to data analysis and interpretation, drafting of the manuscript, critical revision of the manuscript and approval of the final manuscript.

\section{REFERENCES}

1. Kim JW. Questioning the evidence behind the Saturation Model for testosterone replacement therapy in prostate cancer. Investig Clin Urol 2020;61:242-9.

2. Morgentaler A, Traish AM. Shifting the paradigm of testosterone and prostate cancer: the saturation model and the limits of androgen-dependent growth. Eur Urol 2009;55:310-20.

3. Morgentaler A, Benesh JA, Denes BS, Kan-Dobrosky N, Harb D, Miller MG. Factors influencing prostate-specific antigen response among men treated with testosterone therapy for 6 months. J Sex Med 2014;11:2818-25. 
4. Khera M, Bhattacharya RK, Blick G, Kushner H, Nguyen D, Miner MM. Changes in prostate specific antigen in hypogonadal men after 12 months of testosterone replacement therapy: support for the prostate saturation theory. J Urol 2011;186:1005-11.

5. Rastrelli G, Corona G, Vignozzi L, Maseroli E, Silverii A, Monami M, et al. Serum PSA as a predictor of testosterone deficiency. J Sex Med 2013;10:2518-28.

6. Marks LS, Mazer NA, Mostaghel E, Hess DL, Dorey FJ, Epstein JI, et al. Effect of testosterone replacement therapy on prostate tissue in men with late-onset hypogonadism: a randomized controlled trial. JAMA 2006;296:2351-61.

7. Kacker R, Hult M, San Francisco IF, Conners WP, Rojas PA, Dewolf WC, et al. Can testosterone therapy be offered to men on active surveillance for prostate cancer? Preliminary results. Asian J Androl 2016;18:16-20.

8. Ho SM, Damassa D, Kwan PW, Seto HS, Leav I. Androgen receptor levels and androgen contents in the prostate lobes of in- tact and testosterone-treated Noble rats. J Androl 1985;6:27990.

9. Wright AS, Douglas RC, Thomas LN, Lazier CB, Rittmaster RS. Androgen-induced regrowth in the castrated rat ventral prostate: role of 5alpha-reductase. Endocrinology 1999;140:450915.

10. Bhasin S, Woodhouse L, Casaburi R, Singh AB, Mac RP, Lee $\mathrm{M}$, et al. Older men are as responsive as young men to the anabolic effects of graded doses of testosterone on the skeletal muscle. J Clin Endocrinol Metab 2005;90:678-88.

Received: 22 May, 2020 - Accepted: 28 May, 2020

Corresponding Author: Abraham Morgentaler (iD)

Men's Health Boston, Department of Surgery (Urology), Beth Israel

Deaconess Medical Center, Harvard Medical School, Boston, MA 02467, USA

TEL: +1-617-277-5000, FAX: +1-617-277-5444

E-mail:amorgent@yahoo.com

https://doi.org/10.4111/icu.2020.61.4.452 